\title{
COLLECTIVE SELF-ORGANIZED HOUSING: A RESEARCH STUDY TO OPTIMIZE BUILDING TECHNOLOGIES, IMPROVE EFFICIENCY AND REDUCE BUILDING CONSUMPTIONS
}

\author{
SILVIA BRUNORO \& GIACOMO BIZZARRI \\ Department of Architecture, University of Ferrara, Italy
}

\begin{abstract}
This paper illustrates the potentialities of the collective self-organized (CSO) housing model as it is plainly defined within the PROFICIENT project: "SME network business model for collective selforganized processes in the construction and retrofit of energy-efficient residential districts" (EU 7th Framework Program 2012-2016). The sharing of services and efficient building technologies represent a growing strategy that can fulfill the goal of the 20-20-20 EU energy policies. The self-organized housing process - through which a group of homeowners carry out new construction and retrofitting projects on a district scale - reflects a raised awareness towards sustainability and the increasing self-managing capabilities of European society. This can lead to communities with a shared approach to daily tasks and a strong communal life, such as in cohousing, where people choose to live in a residential community in shared services, green spaces, collective areas and low-energy buildings. The main characteristics of an optimized energy-saving technologies approach and energy sources at a district level in CSO are examined in this study, mainly considering some realized case studies, demonstrating that the sharing of goods and services can reduce living costs as energy services are optimized.

Keywords: collective self-organized housing, optimized technologies, energy saving, NzeB.
\end{abstract}

\section{INTRODUCTION}

Collective self-organized (CSO) housing refers to a group of people that act together to organize the processes of formation, requirement definition, planning, design, implementation and/or maintenance of their own housing project [1]. Most of the current collective housing projects pay a special interest in energy efficiency and sustainability issues. CSO projects require a certain level of community involvement, and a high level of participation in the project development process: they comprehend different typologies depending on the degree of communal or private living, self or collective organization, participation to the design and construction process as well as differing support from the local/central authorities [2]. CSO housing projects are based on sustainability principles: energy saving and green buildings. There is a relation between social cohesion within the project or complementary lifestyles and ambitions on sustainability and energy-efficient buildings. Affordable and socially designed homes are well designed when the community starts with clear and shared intentions from the beginning. Moreover, the social cohesion during the in-use phase of the project is strengthened when there are common facilities, especially when maintenance is carried out by the community. One can get, in this way, savings and benefits which are not only economic but also environmental [3].

This paper is based on the results of the research project "PROFICIENT-SME network business model for collective self-organized processes in the construction and retrofit of energy-efficient residential districts" (EU 7th Framework Program 2012-2016; http://www.proficient-project.eu/). The research project PROFICIENT (2013-2016) aimed to create large business opportunities for small and medium-sized enterprises (SMEs) in the 
construction sector by exploiting the newly emerging process of CSO housing for constructing and retrofitting energy-efficient residential districts.

By means of a platform (http://cso.house/), information and tools are provided to help stakeholders in the development of setting up a CSO housing organization, and to support them throughout the implementation and operation stages.

CSO housing can comprehend both new construction and retrofitting/refurbishment projects. The building process is generally issued by a group of non-professional clients that are the current (in the case of retrofitting) or future (in the case of newly built housing) inhabitants of the project. As a result, they do not only have an interest in choosing the optimal solution in terms of investment costs, but the energy and maintenance costs during the lifecycle of the project should also be an important part of their decision-making process. This trend offers opportunities for SMEs such as architects, engineers and contractors and Energy Service Companies (ESCOs or RESCOs, when energy comes from renewable sources) whose services are of use in a CSO housing project. Promoting CSO housing initiatives in urban regeneration or in developing new districts to become energy-efficient and more sustainable places to live means that SME business opportunities are improved. The community is considered as a collective of individual end-users that will be able to take initiative in the design and building phases and/or steer their own collective energy-efficient and community-oriented housing project.

\section{THE MULTI-CRITERIA ANALYSIS MATRIX FOR THE DEFINITION OF ENERGY-EFFICIENT BUILDING TECHNOLOGY INTO THE CSO HOUSING PROCESS}

Nowadays, climatic change is demanding attention from alternative energies. For this reason, the opportunity to co-produce energy and to optimize urban services is rapidly gaining importance. Many status symbols such as independent central heating or cars are losing their value and people are showing more interest in saving money, besides qualitative living. How CSO projects can contribute to sustainable neighbourhoods and urban development, as defined by social and ecological aspects, was investigated in PROFICIENT, mainly in the Work Package 4 "Business case for technology solutions", for which the main objective was to identify the most effective technology solutions in the area of building systems and district energy systems and to investigate the most appropriate business case to be implemented by SMEs on a large scale [6]. The focus is on exploring driven technologies and services that are transferable to the district level (building and long-term economic, social and environmental effects) imprinted in long-term economic and cost-effective solutions. The adoption of energy-efficient building technologies in CSO construction is a major challenge but has the potential to make a dramatic impact on sustainable practices. When addressing these challenges, it is important to emphasize how decisions can be made, and to identify the range of existing and eligible technologies to be optimized, by transferring them to an exemplary business case.

Technologies can be divided into two main categories:

- Building objects: foundations, opaque and transparent facades, roofs. The parameters used to define energy performances are: U-value, shading value, use of low-impact materials and, at $\mathrm{km} 0$, the adoption of strategies for the recycling and recovery of materials and waste. They only have a direct impact on the end uses, since they do not directly affect the energy-transformation processes. This does not mean that their importance is lesser, since it is commonly known that a building envelope with low thermal transmittance (U-value) has the potential to lower the 
energy requirements for both heating and cooling. Architectural technologies, hence, should be put in an ideal column, placed on the right of the end-uses section, releasing their benefits throughout, independently from the different combinations.

- Energy supply and generation objects: plants and, generally, all the devices where the energy transformation processes take place (i.e. district energy networks, main building plants, devices, etc.).

This paper focuses on the second category: energy supply and generation objects at the district level. Most of the decision-making process assessment tools developed by national or international research organizations (e.g. BREEAM, LEED, SBTOOL, ITACA, MINERGIE) give a comprehensive analysis for the environmental assessment of buildings by covering several aspects related to building construction, use and demolition (such as energy use, water use, infrastructural connection and indoor comfort) [4].

In strong contrast to the professional construction market led by real-estate developers, municipal or housing corporations are the civil market of CSO housing projects: this market is characterized by having non-professionals with no expertise in charge, who are not necessarily familiar with the codes, procedures, processes and vocabulary of planning and building a housing project. To provide products or services to the latter type of client is difficult from a professional point of view and it requires an adjustment of approach, language and functional explanation of what is offered. From the clients' perspective, the information provided by suppliers is considered with a portion of distrust. The real issue is: how to bridge the dichotomy? By enabling and supporting the communication between supply and demand, making offers more easily comparable, and having a kind of standardized set of materials available to partners [5].

The emphasis is put on identifying cost-effective solutions with high, long-term utility considering the environmental performance criteria for the end users in upgrading the available solutions and optimizing the business cases for more successful and larger-scale market exploitation by SMEs, by considering product/market alternatives, performance and costs, maintenance and durability.

The achievement of the target of optimization may be fulfilled through a proposed specific procedure based on a multi-criteria approach, "from sources to end uses", by benchmarking relevant plant technologies and their application potential for CSO housing projects. To identify and benchmark the potential application of existing plant technologies to CSO projects, a general matrix (Table 1) was created to organize the technologies in relation to their effect on the energy-conversion supply chain, from the sources, renewable or fossil, to the end uses. Plant technologies are listed by considering the following parameters:

- Source of energy: this indicates which kind of energy the technology is derived from. There are two main macro-groups in which energy sources can be divided. One is renewable sources, the second is non-renewable sources. In the first group, energy that is collected from resources that are naturally replenished on a human timescale, such as sun, wind, water, waves, and geothermal heat, are included. The second group comprehends the resources that do not renew themselves at a sufficient rate for sustainable economic extraction in meaningful human time frames. An example is carbon-based, organically derived fuel.

- Vector: this indicates a temporary status of energy within the delivery and transformation processes that take place from sources to end uses.

- Technical products: these products are available on the market, and are able to transform specific sources in specific end uses; in this case, through vectors, according to typical technology efficiencies. 
Table 1: Benchmarking plant technologies from source to end users (extract) [6].

\begin{tabular}{|l|l|l|l|l|l|}
\hline LEVEL 1 & LEVEL 2 & LEVEL 3 & LEVEL 4a & LEVEL 4b & LEVEL 5 \\
\hline $\begin{array}{l}\text { Source of } \\
\text { energy }\end{array}$ & Vectors & $\begin{array}{l}\text { Technical } \\
\text { products }\end{array}$ & $\begin{array}{l}\text { Main central plant } \\
\text { at CSO level }\end{array}$ & $\begin{array}{l}\text { Terminal } \\
\text { devices at } \\
\text { CSO level }\end{array}$ & End uses \\
\hline RENEWABLE ENERGY & \multicolumn{5}{|l|}{} \\
\hline $\begin{array}{l}\text { Solar } \\
\text { energy }\end{array}$ & Hot water & Solar panel & $\begin{array}{l}\text { Heat exchangers } \\
\text { (water-water) }\end{array}$ & $\begin{array}{l}\text { Radiant } \\
\text { underfloor } \\
\text { heating and } \\
\text { cooling }\end{array}$ & $\begin{array}{l}\text { Heating, } \\
\text { sanitary water, } \\
\text { cooling }\end{array}$ \\
\hline & Electricity & $\begin{array}{l}\text { Photovoltaic } \\
\text { module }\end{array}$ & $\begin{array}{l}\text { Heat } \\
\text { pump/compression } \\
\text { chillers }\end{array}$ & $\begin{array}{l}\text { Radiators, fan } \\
\text { coils }\end{array}$ & $\begin{array}{l}\text { Heating, } \\
\text { sanitary water, } \\
\text { cooling, } \\
\text { electrical end } \\
\text { uses }\end{array}$ \\
\hline
\end{tabular}

- Main central plant at the CSO level: this indicates which centralized plants work with the determined energy source (centralization is intended as the first grade of energy efficiency).

- Terminal device at the CSO level: this indicates which are the most diffused terminal devices related to that peculiar energy vector.

- End uses: from the point of view of the end users, this indicates for which use the technology is supplied.

There are two different ways of reading the matrix: 1) navigate from the left to the right, proceeding from the primary energy to the end uses; 2) start from the consumption end, following in the opposite direction. The first objective of the matrix consists of providing a clear picture of where and how each technology influences the energy supply chain. Different colours have been given to easily identify the relations linking vectors, technologies and end uses: items related to electricity are represented with red fonts (this is true for the vector electricity itself, for the technologies (e.g. photovoltaic modules, CHP) and for the electrical end use), heating is in blue (dark blue, sanitary water, and light blue, heating), cooling is shown in grey, etc.

The question that one has to keep in mind when approaching the problem is: "how do I identify the technologies that have to be optimized?" Which are the parameters to be monitored and "understood"? At least they are not homogeneous (e.g. plants efficiency, electricity and gas costs, etc.).

Hence, a specific multi-criterial methodology based on a "score procedure" has been proposed to overcome this issue:

1 We can identify different sections for each category that influences the business cases: 1) HVAC systems; 2) electrical plants; and 3) energy costs and management.

2 For each section, a range of possible optimization/retrofit options is provided.

3 A "score" procedure is implemented to identify the best option for each section (e.g. best available technologies for sections 1 and 2, etc.).

4 The scores are given in relation to the effectiveness (economic, energy, etc.) of each single option and its compliance with SME activities and resources.

5 The ideal business case has to be built by considering the combination of the best solutions identified in the four-sections analysis. 
The efficiency of existing technologies can be evaluated by benchmarking according to four macro-categories that describe the parameters: technology pre-feasibility, financial pre-feasibility, energy and environment, other relevant parameters (e.g. SME compliance). There are examined in detail below:

- Technology pre-feasibility (Table 2): this section examines the grade of feasibility of one technology in comparison to another. "Is the plant feasible?" assignment criterion: score 1-2 = no real optimization of the state-of-the-art plant configuration ( 1 for complicated feasibility, 2 for easy feasibility); score $3-5=$ if there is an optimization of the state-of-the-art plant configuration (3 for complicated feasibility, 4 for easy feasibility and no substantial increase in efficiency, 5 for easy feasibility and increase of efficiency).

- Financial pre-feasibility (Table 3): this section refers to the question, "Is the intervention financially feasible?" given i) the CAPEX (CAPital Expenditure: capitals used by a company to acquire or upgrade physical assets such as equipment, property, or industrial buildings) and ii) the OPEX (OPErating EXpenditure is an ongoing cost for running a product, business, or system). Assignment criterion: scores from 1 to 2 for CAPEX ( 1 = high CAPEX, $2=$ low CAPEX), scores from 0 to 3 for $\operatorname{OPEX}(0=$ high OPEX, 3 = low OPEX).

- $\quad$ Energy and environment (Table 4): this section considers the environmental impact of the technology, and is described by the following questions: i) Plants: "Is the technology environmental friendly, allowing energy savings and GHG emission reduction?"; ii) Envelope: "Is the technology environmental, using renewable and/or recyclable materials?"; "Is the technology environmentally friendly, using $\mathrm{km} 0$ materials?". Assignment criterion: $1=$ no; $2=$ it depends; $3=$ yes.

- Others (Table 5): in this section, time-dependent factors are considered, such as market availability and user demand, and the section refers to the questions: "Can SMEs handle this technology?"; "Is the technology close to the market?"; "Does the technology fit the end user's demand?" Assignment criterion for the questions, "Can SMEs handle this technology?" and "Is this technology close to the market?": $1=$ no; 2 = it depends; 3 = yes. Assignment criterion for the question, "Does it fit the end user's demand?": 1 = not (it does not fit); 2 = scarcely; 3 = on average; $4=$ yes; 5 = ideal.

By following the above criteria, this method is aimed at proposing a fast and easy-to-use preliminary assessment in order to give non-experts indications of which strategy is worth being further investigated. In such a perspective, the limitations given by this approach are counterbalanced by the scope of the methodology.

\section{CASE STUDY OF OPTIMIZATION: THE CIVAGO CASE IN ITALY}

A clear example of how to identify the technology application that is needed for optimization comes from direct case studies that are described and analysed in a deliverable format, which can thus represent an overview of the possible solutions to be transferred to the user via scientific knowledge. A real RESCO example is the hydro plant realised by Becquerel on the River Rumale, north-west of the village of Civago, in the Emilia Romagna Region (Fig. 1). The plant seeks to fulfil the high standards of supplying electricity to all the houses of the village on a collective basis. This SME-driven initiative has implemented an existing technology on the basis of a brand-new business application (i.e. the CSO approach plus crowdfunded investment, representing an innovative, exemplary business model for the future). 


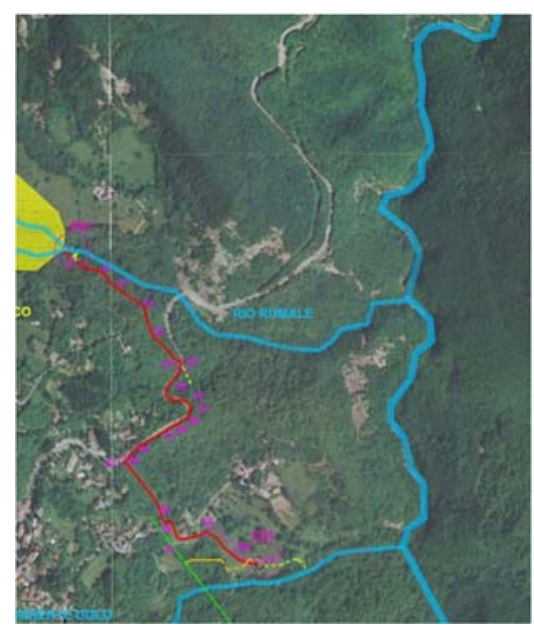

Figure 1: Overview of the project area.

The residents of Civago were seeking some opportunities to increase the efficiency of their houses. They were considering standard actions such as either the installation of PV modules on the rooftop, or the usage of biomass-fired heaters, or to invest money for improving the thermal resistance characteristics of the envelopes of the buildings.

Some of the inhabitants of Civago decided to start a consortium in order to evaluate more complicated interventions/business cases such as local district heating solutions, the implementation of local aqueducts with micro turbines, and the adoption of larger systems to generate electricity from renewable sources such as a small wind turbine or a mini-hydro plant. Even though the potential of the latter systems was considerable, the promoters encountered difficulties from the beginning due to the barriers associated with the high expertise required for developing these business cases and the high risks that characterize the early steps. At the same time, a local SME, Becquerel Electric, partner of Proficient Consortium, with a great deal of experience in the energy sector, was investigating the potential of installing an industrial power plant in the wider area around Civago; the two actors naturally met on the field and decide to cooperate together in a sort of an informal consortium. This section presents the application of a multi-criteria decision analysis (MCDA) procedure that has assisted the SME to identify, together with the citizens, the best available solution for the optimization of the energy demand of Civago village [7]. The residents were initially focusing on the optimization of the electricity requirements of their houses but not on the thermal demand, since most of the houses were not used continuously and thermal needs were assisted by wood-fired fireplaces or boilers.

Given the specific location, several business cases were available and have been considered:

1. The installation of PV plants (to be installed on the rooftop);

2. The installation of wind turbines, small and local, or through a district approach;

3. The installation of a hydro plant to provide electricity to the whole village;

4. Combined Heat and Power (CHP) fed by local biomass, built at the district level;

5. Geothermal heat pump.

Other options, such as gas-fired technologies and the installation of air-based heat pumps, were discarded because of the difficulties associated with either delivering natural gas in the area or the very low efficiency of the heat pump due to the cold outdoor temperatures 
in winters in Civago. In the multi-criterial analysis tool, the first section provides a pre-assessment that helps the main actors (e.g. CSO actuators, SMEs, community) to initiate a rough selection of the available options/business cases.

By considering the different technologies available on the market, different technology options were investigated by benchmarking their fundamental parameters. This approach aims to identify the action limits of optimization, acting directly on each specific transformation process. Hence, the relevant question here is: "how do we optimize the business case?"; meaning, which strategies can be implemented in order to increase the particular efficiency of a technology or the related economic fundamentals. There are direct actions and indirect actions, as well; some of them, especially the ones related to the economic fundamentals, do not even depend on the will of the SMEs, but reflect wider market trends.

The rating process is carried out by crediting each technology solution with values. The crediting system is based on attributing a value ranging from 1 to 5 to each of the analysis factors of the energy supply and generation objects (letters from A to D are reported in the tables).

Table 2: Pre-assessment section of MCDA [7].

\begin{tabular}{|c|c|c|c|c|c|}
\hline \multirow{2}{*}{$\begin{array}{l}\text { Electrical } \\
\text { plants }\end{array}$} & \multirow{2}{*}{$\begin{array}{l}\text { Average } \\
\text { electrical } \\
\text { efficiency }\end{array}$} & \multicolumn{4}{|c|}{ Technology pre-feasibility } \\
\hline & & $\begin{array}{l}\text { Yes/no/ } \\
\text { it depends }\end{array}$ & Notes & Score $^{a}$ & Notes \\
\hline $\begin{array}{l}\text { Photovoltaic } \\
\text { plants }\end{array}$ & $8-16 \% 0^{2}$ & $\therefore$ & $\begin{array}{l}\text { Mountains limit the } \\
\text { available solar radiation }\end{array}$ & 3 & $\begin{array}{l}\text { Feasible, but PV production } \\
\text { can be very low in many } \\
\text { systems because of } \\
\text { mountains }\end{array}$ \\
\hline Wind plants & $\begin{array}{l}\text { About } 50 \% \\
(70-85 \% \text { of } \\
\text { Betz limit } \\
59.3 \%)\end{array}$ & 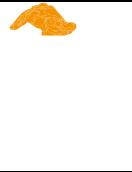 & $\begin{array}{l}\text { Mountains can shelter } \\
\text { wind when it comes from } \\
\text { a certain direction, } \\
\text { limiting the site } \\
\text { production }\end{array}$ & 3 & - \\
\hline Hydro plants & $70-85 \%{ }^{4}$ & & - & 5 & $\begin{array}{l}\text { Flexible, several rivers with } \\
\text { high potential in the } \\
\text { surroundings }\end{array}$ \\
\hline $\begin{array}{l}\text { CHP (fed by } \\
\text { gas) }\end{array}$ & $179 \%{ }^{4}$ & & $\begin{array}{l}\text { Location not supplied by } \\
\text { gas network }\end{array}$ & - & - \\
\hline $\begin{array}{l}\text { CHP (fed by } \\
\text { biomasses) }\end{array}$ & $172 \%$ & & & 4 & $\begin{array}{l}\text { Flexible, biomass available } \\
\text { in the surroundings }\end{array}$ \\
\hline Heat pumps & n.a. ${ }^{5}$ & & $\begin{array}{l}\text { Not feasible because of } \\
\text { the low temperature of } \\
\text { the outdoor air }\end{array}$ & 1 & $\begin{array}{l}\text { Grid connection available } \\
\text { everywhere }\end{array}$ \\
\hline $\begin{array}{l}\text { Geothermal } \\
\text { heat pumps }\end{array}$ & n.a. ${ }^{5}$ & & $\begin{array}{l}\text { Feasible but not cost- } \\
\text { effective }\end{array}$ & 2 & $\begin{array}{l}\text { Grid connection available } \\
\text { everywhere but pipe } \\
\text { connection is difficult }\end{array}$ \\
\hline
\end{tabular}

${ }^{a}$ How to appoint the technology feasibility scores: scores from 1 to 2 if there is no real optimization of the state-ofthe-art plant configuration (1 for complicated technologies).

${ }^{1}$ Only if biomass comes from a local supply chain (70 km radius from the boilers).

${ }^{2}$ Standard thermal efficiencies, COP for heat pump, efficiency adjusted according to exergy analysis for CHP; fossil and renewables are considered simply.

${ }^{3}$ Efficiency typically depends on the power utilization factor of the boiler (instantaneously required thermal power divided by the nominal thermal power of the boiler).

${ }^{4}$ Efficiency for CHP is defined in accordance with the exergy allocation factor procedure [11].

${ }^{5}$ Refers to COP considering a heat pump fed by electricity: COP $=4$ for standard heat pump; 5 for geothermal heat pump; average national electrical efficiency $=0.4$. 
Some scores are given to how much a certain business case/technology is compliant to the specific site. Hydro plants and biomasses are, for instance, in the specific case of Civago, very desirable, since they are abundant on the site. Solar systems are not ideal solutions because, independently from the sky albedo that characterizes that area, the shadowing given by the high mountains that surround the village limits the available radiation, especially during winter. Wind system potential is itself limited by the little wind availability caused by the orography, and geothermal heat pumps can be affected by unexpected costs due to problematic drilling in rocky terrains.

The orography, together with the cost of excavation, can represent a limit in CHP fed by biomasses that has to be taken into account. In the multi-criterial analysis then, a second step (Table 2) is introduced to provide a pre-assessment of the financial feasibility of the investigated options/business cases, especially compared to the environmental and energy benefits. Three items are provided in this section, the first evaluates if there is a general economic feasibility of the business case, the second and third consider if the option is environmentally friendly in terms of the production of renewable energy and/or energy savings and greenhouse gas (GHG) abatement potential. Scores are given according to a specific key.

The analyses show that the best options are the hydropower plant and the cogeneration plant fed by local biomasses.

Table 3: Financial feasibility and energy and environment section of MCDA [7].

\begin{tabular}{|c|c|c|c|c|c|c|c|}
\hline \multirow{3}{*}{$\begin{array}{l}\text { Electrical } \\
\text { plants }\end{array}$} & \multicolumn{3}{|c|}{ Financial pre-feasibility } & \multicolumn{4}{|c|}{ Energy and environment } \\
\hline & \multirow[b]{2}{*}{\begin{tabular}{|l|} 
Yes/no/ \\
it depends
\end{tabular}} & \multirow[b]{2}{*}{ Score $^{b}$} & \multirow[b]{2}{*}{ Notes } & \multicolumn{2}{|c|}{$\begin{array}{l}\text { Is the technology } \\
\text { environmentally friendly } \\
\text { and does it allow energy } \\
\text { savings? }\end{array}$} & \multicolumn{2}{|c|}{$\begin{array}{l}\text { Is the technology } \\
\text { environmentally friendly, } \\
\text { allowing reduction in } \\
\text { GHG emissions? }\end{array}$} \\
\hline & & & & $\begin{array}{l}\text { Yes/no/ } \\
\text { it depends }\end{array}$ & Score $^{c}$ & $\begin{array}{l}\text { Yes/no/ } \\
\text { it depends }\end{array}$ & Score $^{\mathrm{c}}$ \\
\hline $\begin{array}{l}\text { Photovoltaic } \\
\text { plants }\end{array}$ & & 4 & $\begin{array}{l}\text { Capex: low } 2 \text { pt } \\
\text { Opex: standard } 2 \text { pt }\end{array}$ & & 2 & & 2 \\
\hline Wind plants & & 3 & $\begin{array}{l}\text { Capex: high } 1 \mathrm{pt} \\
\text { Opex: standard } 2 \mathrm{pt}\end{array}$ & & 1 & & 1 \\
\hline Hydro plants & & 5 & $\begin{array}{l}\text { Capex: medium } 2 \mathrm{pt} \\
\text { Opex: very } \\
\text { advantageous since } \\
\text { the revenues from } \\
\text { the electricity self- } \\
\text { production } 3 \mathrm{pt}\end{array}$ & & 3 & & 3 \\
\hline $\begin{array}{l}\text { CHP } \\
\text { (fed by gas or } \\
\text { by biomasses) }\end{array}$ & & 4 & $\begin{array}{l}\text { Capex: high } 1 \mathrm{pt} \\
\text { Opex: very } \\
\text { advantageous since } \\
\text { CHP + availability } \\
\text { of local biomass } 3 \mathrm{pt}\end{array}$ & & 3 & & 3 \\
\hline $\begin{array}{l}\text { Heat pumps } \\
\text { Geothermal } \\
\text { heat pumps }\end{array}$ & & 3 & $\begin{array}{l}\text { Capex: high } 1 \mathrm{pt} \\
\text { Opex: standard } 2 \mathrm{pt}\end{array}$ & 2 & 2 & & 1 \\
\hline
\end{tabular}

${ }^{b}$ How to appoint the financial feasibility scores: appoint scores from 1 to 2 to CAPEX $(1=$ high CAPEX, $2=$ low CAPEX), then add scores from 0 to 3 to $\operatorname{OPEX}(0=$ high CAPEX, $3=$ low $)$.

${ }^{c}$ How to appoint the scores to the questions: "Is the technology environmentally friendly and does it allow energy savings?", "Is the technology environmentally friendly, allowing reduction in GHG emissions?", "Can SMEs handle this technology?" and "Is this technology close to the market?":

appoint 1 if no, 2 if it depends, 3 if yes 
Table 4: Others (management and market) section of MCDA [7].

\begin{tabular}{|l|l|l|l|l|l|l|}
\hline \multirow{2}{*}{$\begin{array}{l}\text { Electrical } \\
\text { plants }\end{array}$} & \multicolumn{5}{|c|}{ OTHERS } \\
\cline { 2 - 7 } & \multicolumn{2}{|c|}{$\begin{array}{c}\text { Can SME handle this } \\
\text { technology? }\end{array}$} & \multicolumn{2}{|c|}{$\begin{array}{l}\text { Is the technology close to } \\
\text { the market? }\end{array}$} & \multicolumn{2}{|l|}{$\begin{array}{l}\text { Does the technology fit } \\
\text { the end user's demand? }\end{array}$} \\
\cline { 2 - 7 } & $\begin{array}{l}\text { Yes/no/ } \\
\text { it depends }\end{array}$ & Score & $\begin{array}{l}\text { Yes/no/ } \\
\text { it depends }\end{array}$ & Score & $\begin{array}{l}\text { No, poorly, } \\
\text { on average, } \\
\text { yes, ideal }\end{array}$ & Score \\
\hline $\begin{array}{l}\text { Photovoltaic } \\
\text { plants }\end{array}$ & & 2 & & 3 & On average & 3 \\
\hline Wind plants & N & 2 & & 2 & On average & 2 \\
\hline Hydro plants & & 2 & & 2 & Ideal & 5 \\
\hline $\begin{array}{l}\text { CHP } \\
\text { (fed by gas or } \\
\text { by biomasses) }\end{array}$ & & 2 & & 2 & Ideal & 5 \\
\hline $\begin{array}{l}\text { Heat pumps } \\
\text { Geothermal } \\
\text { heat pumps }\end{array}$ & & 2 & & 2 & On average & 3 \\
\hline
\end{tabular}

"How to appoint the scores to the questions: "Is the technology environmentally friendly and does it allow energy savings?", "Is the technology environmentally friendly, allowing reduction in GHG emissions?", "Can SMEs handle this technology?" and "Is this technology close to the market?": appoint 1 if no, 2 if it depends, 3 if yes.

'How to appoint the scores to the question "Does it fit the end user's demand?": appoint 1 if not (it does not fit), 2 if scarcely, 3 if on average, 4 if yes, 5 if ideal.

The next section focuses on the management issues, mainly answering the question of whether the investigated technologies can be handled or not by SMEs, and if it is possible to consider the technology mature enough for the market. Finally, there is an evaluation of how much every option fits the final end user's energy demand. Again, scores are given and in this case it becomes clear that certain technologies and the related business cases are only feasible thanks to the expertise of a SME sponsoring the initiative. The results section simply provides the sum of the scores, option by option, adding a brief focus on possible future trends for Capital Expenditures (CapEX) and Operating Expenditures (OpEX). The final analysis might be of interest in all of the cases where some integrated solutions (i.e. 'upgraded' solutions) are considered, because of the long-term development that often characterizes these options.

The results of the multi-criteria approach (Tables 2-5 and Fig. 2) show that the building of a hydro plant shall be considered as the best available option.

Table 5: Results of MCDA [7].

\begin{tabular}{|l|l|l|l|}
\hline Electrical plants & \multicolumn{3}{|c|}{ Results } \\
\cline { 2 - 4 } & Total score & $\begin{array}{l}\text { CAPEX future } \\
\text { trends }\end{array}$ & OPEX future trends \\
\hline Photovoltaic plants & 19 & Stable & Stable \\
\hline Wind plants & 14 & Stable & Stable \\
\hline Hydro plants & 25 & Stable & Increasing profits \\
\hline $\begin{array}{l}\text { CHP (fed by gas or } \\
\text { by biomasses) }\end{array}$ & 25 & Lowering costs & Increasing profits \\
\hline $\begin{array}{l}\text { Heat pumps } \\
\text { Geothermal heat } \\
\text { pumps }\end{array}$ & 15 & Stable & Lowering costs \\
\hline
\end{tabular}




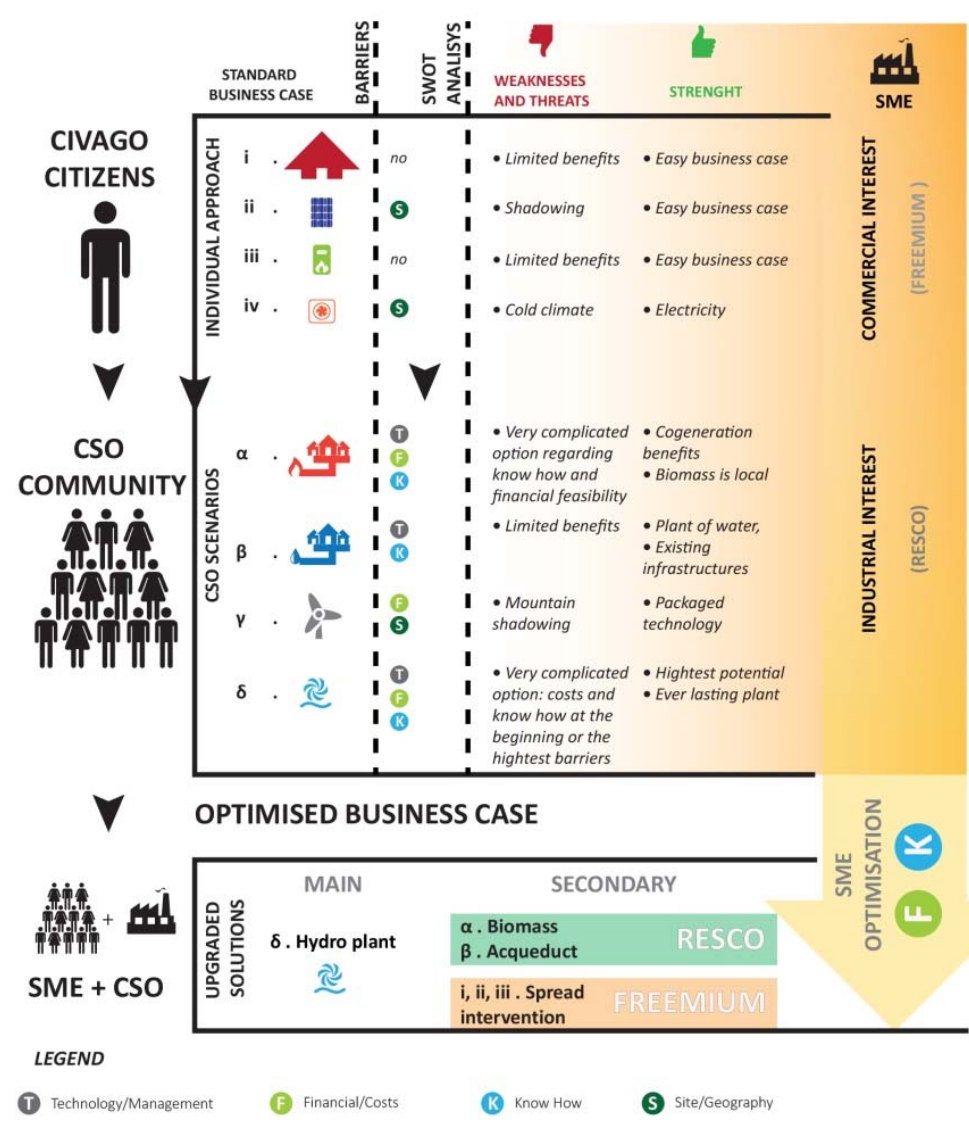

Figure 2: Dashboard describing how the SME approaches the standard business cases of citizens and community from commercial (franchise freemium) and industrial (RESCO) strategies, respectively [7].

This tool aims to be very helpful for an SME that is approaching RESCO enterprises or consortiums; however, because of the necessity of high expertise in using the tool, it has not been developed to be used directly by citizens/CSO actors, but fundamentally through the qualified assistance of skilled users, such as architects, engineers, and managers.

The procedure developed in this section can be considered as an extension of procedures that highlight prevalently thermal optimization; therefore, there are interventions that should be made: the optimizing envelope generates positive results regardless of the energy and electricity supply. It is important here to give a different point of view through which financial, management and operational parameters are added to those that are technical. In this sense, this methodology provides a spreadsheet model that can help designers in putting together heterogeneous variables determining new types of business cases. At this point, adding a "decision-making" matrix - which also takes in account other analytical and more holistic parameters (e.g. if technology is SME friendly, if it is approachable by end users, etc.) - by adding new topics (financing, SME compliance, and market analyses) is giving an 
enhanced content to the MCDM matrix that can give indications to SMEs on the CSO housing platform.

Finally, the combination of interests of the local actors and the SME has resulted in a real optimization of the business cases (intended as a cost-effectiveness study used to analyse a specific business scenario): an economic planning tool for identifying and comparing multiple alternatives for pursuing an opportunity and then proposing the course of action that will yield the most value. The value is analysed regarding the defined key business metrics (i.e. financial and non-financial impacts of the business case).

In addition to the standard interventions, the integrated approach between the CSO and the SME helped in overpassing the barriers, solved the early-stage problems, and identified an order in the actions to be undertaken. In the business-as-usual scenario, the electricity requirements are fulfilled thanks to a simple connection to the grid.

This connection does not cost too much in terms of CAPEX (does not vary the dwelling values for existing cases and does not imply extra costs for new construction); however, it can be a heavy entry in the OPEX list, due to the high cost of electricity. Moreover, the electricity from the grid has hidden energy and environmental costs, in terms of primary fossil energy consumptions, GHGs, and pollutant emissions that come from the way the electricity is produced in a certain country. This situation suggests we should consider a possible way to evaluate shifts from the business-as-usual scenario, adopting solutions where the electricity is locally produced or by plants fed by renewable sources (e.g. mainly biomasses, solar, hydro, wind), or through a more rational utilization of fossil energy (e.g. combined heat and power plants).

\section{CONCLUSIONS}

CSO housing groups represent a continuously growing share of large-scale developments in housing. The PROFICIENT project is looking for large-scale CSO housing developments, and the main question is, which kind of SME company is prepared to match with the current demands of these client groups from the development process of the project to technical and economical details of district-oriented energy service provision.

Given the complexity of the analyses associated with the various different scenarios, the multi-criteria matrix is an important tool to identify the most appropriate technical solution based on efficiency, effectiveness, and optimization criteria. This tool is a good sample for an interactive device that support the needs of the construction and building service industry to find quick solutions for complex holistic technological demands.

The aim of the research is to define a procedure in order to identify which of the energyefficiency technologies examined are potentially perfectible and how they can then be used to improve energy efficiency in CSO housing districts. This decision-making matrix for technology optimization can be helpful for the network to focus on the best ESCO/RESCO solutions in a tender. The real optimization lays in the possibility of combining standard technologies with new development strategies, such as crowdfunding and/or e-commerce platforms, where a consortium of SMEs can establish the efficient commercial network, providing the CSO housing actors services that are normally far beyond their "business as usual". The PROFICIENT project's main aim is to promote large-scale CSO housing developments, by encouraging SME companies to match with the current demands of these client groups from the development process of the project to technical and economical details of district-oriented energy service provision. A central and major task to fulfil the specific demands of the clients - in this case, the CSO housing groups - is the delivery of an energy service solution at the district level while promoting high-end technical solutions and concepts demanded by the client group. At the same time, the perhaps shared profit created 
by the above-mentioned efforts should motivate the SMEs and the CSO housing groups to cooperate intensively.

The optimization approach chosen for the Civago case study, as presented here, has already been successfully followed In other relevant case studies and could be suggested as a reference for good practice for CSO initiatives. The strict cooperation between SME and CSO communities can be considered itself as an optimized business case that has led to upgraded solutions.

The lesson learnt here is that the creation of a synergy between a SME with a specific and valued expertise and a CSO community has the potential for multiplying possible actions through a leverage effect, enabled by crowd funding for the driving initiative. This is no doubt the concrete optimization of a business-as-usual scenario.

\section{ACKNOWLEDGEMENTS}

The research leading to these results has received funding from the European Community's Seventh Framework Programme under Grant Agreement No. 312219 (Project PROFICIENT). Special thanks to Becquerel Electric S.r.l. for funding this research, along with the company's research team for the external support given in the preparation of the paper, and their courtesy in supplying the design and images of the case study that are published in this paper.

\section{REFERENCES}

[1] Senge, P., The Necessary Revolution, Nicholas Brealey Publishing: London, 2008.

[2] Lietaert, M., Cohousing's relevance to degrowth theories. Journal of Cleaner Technologies, 18, 2010.

[3] Id22, Co-housing Cultures. Handbook for Self-Organized, Community-Oriented and Sustainable Housing, Jovis: Berlin, 2012.

[4] Yoon, K.P. \& Hwang, C.L., Multiple Attribute Decision Making: An Introduction, SAGE Publications, 1995.

[5] IEA-RETD, Business models for renewable energy in the built environment, 2013.

[6] Luig, K.T. et al., Business Cases for New Solutions Or prototypes, PROFICIENT D 4.5, 2016 (unpublished).

[7] Bizzarri, G. et al., Optimized Business Cases for Upgraded Solutions, PROFICIENT D 4.6, 2016 (unpublished).

[8] PROFICIENT, PROFICIENT research website, http://www.proficient-project.eu/.

[9] CSO, Collective self-organized platform, http://cso.house/.

[10] Becquerel s.r.l., http://www.becquerel.it/.

[11] Bizzarri, G., Local energy policies for Kyoto goals: Ecoabita protocol a key action to reduce energy consumption in residential sector. Energy and Building, 43(9), pp. 2394-2403, 2011. 